\title{
Characterization of Endotrypanum Parasites Using Specific Monoclonal Antibodies
}

\author{
Antonia Maria Ramos Franco/+, Gerzia MC Machado, Roberto D Naiff*, Celia \\ FS Moreira, Diane McMahon-Pratt**, Gabriel Grimaldi Jr
}

\author{
Departamento de Imunologia, Instituto Oswaldo Cruz, Av. Brasil 4365, 21045-900 Rio de Janeiro, RJ, Brasil \\ *Instituto Nacional de Pesquisas da Amazônia, Caixa Postal 478, 69083-000 Manaus, AM, Brasil **DEPH, \\ Yale University School of Medicine, PO Box 3333, New Haven, CT 06510, USA
}

A large number of Endotrypanum stocks (representing an heterogeneous population of strains) have been screened against a panel of monoclonal antibodies (MAbs) derived for selected species of Endotrypanum or Leishmania, to see whether this approach could be used to group/differentiate further among these parasites. Using different immunological assay systems, MAbs considered specific for the genus Endotrypanum (E-24, CXXX-3G5-F12) or strain M6159 of E. schaudinni (E-2, CXIV-3C7-F5) reacted variably according to the test used but in the ELISA or immunofluorescence assay both reacted with all the strains tested. Analyses using these MAbs showed antigenic diversity occurring among the Endotrypanum strains, but no qualitative or quantitative reactivity pattern could be consistently related to parasite origin (i.e., host species involved) or geographic area of isolation. Western blot analyses of the parasites showed that these MAbs recognized multiple components. Differences existed either in the epitope density or molecular forms associated with the antigenic determinants and therefore allowed the assignment of the strains to specific antigenic groups. Using immunofluorescence or ELISA assay, clone E-24 produced reaction with L. equatorensis (which is a parasite of sloth and rodent), but not with other trypanosomatids examined. Interestingly, the latter parasite and the Endotrypanum strains crossreacted with a number of MAbs that were produced against members of the L. major-L. tropica complex.

Key words: Endotrypanum - Kinetoplastida - Trypanosomatidae - mammalian reservoirs - molecular characterization - monoclonal antibodies

Endotrypanum parasites are unique among the Kinetoplastida in that they infect erythrocytes of their mammalian host, the two and three-toed sloths (genera Choloepus and Bradypus, respectively). Inside the erythrocyte the Endotrypanum assumes an epimastigote or trypomastigote form, while in the sandfly and during in vitro culture the parasite assumes promastigote morphology (Shaw 1992). Similarities at the morphological, molecular and biological levels exist between many trypanosomatids isolated from sylvatic insect and/or vertebrate reservoir hosts that make the identification of the medical importance parasites demanding (Shaw 1985). Moreover, the neotropical tree sloths, which are reservoir of at least six Leishmania spe-

This work was supported in part by the Brazilian National Council of Scientific Development and Technology $(\mathrm{CNPq})$ and CAPES/BR.

${ }^{+}$CAPES fellowship and corresponding author. Fax: $+55-21-280.1589$

Received 9 April 1996

Accepted 21 October 1996 cies pathogenic for human (review in Grimaldi \& Tesh 1993), are hosts of Endotrypanum (reviewed in Shaw 1992) and several Trypanosoma species [T. cruzi, T. rangeli, T. leeuwenhoeki, T. preguici and T. legeri] (Montero-Gei 1956, Shaw 1969, Zeledón et al. 1975, Herrer \& Christensen 1980, Miles et al. 1983).

Identification of Endotrypanum strains usually relies on the examination of promastigotes from cultures, and those forms of the parasite are morphological indistinguishable from Leishmania (Croft et al. 1980). More precise taxonomic markers for Endotrypanum, however, have resulted from the application of molecular techniques (Greig et al. 1989, Lopes et al. 1990, Fernandes et al. 1993, Medina-Acosta et al. 1994, Franco et al. 1996). Among the new approaches for identifying Endotrypanum is serodeme analysis using specific MAbs (Lopes \& McMahon-Pratt 1989). In order to extend these observations, here we discuss the results of parasite differentiation of Endotrypanum (comprised of an heterogenous population of reference strains and Amazonian isolates), as characterized by their reactivities with MAbs and using distinct assay systems. 


\section{MATERIALS AND METHODS}

The parasites - The origin (i.e., host species involved or geographical area of isolation) of the 22 Endotrypanum stocks examined in this study, which included reference strains (Medina-Acosta et al. 1994) are given in Table I. The stocks were stored as stabilates at $-190^{\circ} \mathrm{C}$ in liquid nitrogen refrigerators, and the freezing medium used was Schneider's medium containing $10 \%$ fetal bovine serum (FBS) and $8 \%$ dimethylsulfoxide (Grimaldi et al. 1992).

Preparation of samples - Procedures for growing Endotrypanum promastigotes in vitro and for preparation of extracts for serodeme analysis with monoclonal antibodies have been reported previously (McMahon-Pratt et al. 1986). Briefly, promastigotes in the log phase of growth in Schneider's medium were harvested by centrifugation $\left(1,500 \mathrm{x} g\right.$ for $10 \mathrm{~min}$ at $\left.4^{\circ} \mathrm{C}\right)$ and washed twice in phosphate-buffered saline (PBS), $\mathrm{pH}$ 7.3. The final pellet was used for preparation of samples. Antigens of each of the strains tested were prepared as promastigote homogenates containing protease inhibitors (Leon et al. 1992). Prior to analysis, the samples were briefly sonicated using a bath sonicator (RAI Research, Model 250 Ultrasonic cleaner) to homogenize the antigens, and then centrifuged $\left(2,000 \mathrm{x} g\right.$ for $10 \mathrm{~min}$, at $\left.4^{\circ} \mathrm{C}\right)$. Protein concentration was measured by the protein assay method of Bradford (1976), and all samples were resuspended to the same concentration before analysis.

Monoclonal antibodies and immunological assay systems - The MAbs used in this study were produced against membrane components of Endotrypanum (Lopes \& McMahon-Pratt 1989) or Leishmania species (McMahon-Pratt et al. 1986). The following group- or species-specific clones were employed for typing parasites: E-24, CXXX-3G5F12, Endotrypanum sp.; E-2, CXIV-3C7-F5, E. schaudinni; T-11, LXIX 2D8-D7, L. (L.) major; T12, IS1 2G7-F1, L. (L.) tropica; D-2, LXXVIII 2E5A8, L. donovani complex; M-7, IXVIII 1D7-B8, L. mexicana complex; B-20, 22F7-D3, Leishmania $(V$.$) sp.; B-5, VII-2C5-C5, L. braziliensis com-$ plex; B-19, XLIV-5A2-B9, L. (V.) guyanensis; CR, G2G4, cross-reactive to all kinetoplastids (Lopes \& McMahon-Pratt 1989, WHO 1993, Grimaldi \&

TABLE I

Origin and identification of Endotrypanum reference strains and 17 isolates from the Amazon Region, Brazil, which were characterized by monoclonal antibodies in this study

\begin{tabular}{|c|c|c|c|c|}
\hline Stock code & Designation & Species & Geographic origin & Zymodeme \\
\hline \multicolumn{5}{|c|}{ Reference strains } \\
\hline E11 & $\mathrm{MCHO} / \mathrm{CR} / 62 / \mathrm{A}-9^{b}$ & E. monterogeii & Costa Rica & EZ01 \\
\hline E12 & $\mathrm{MCHO} / \mathrm{BR} / 88 / \mathrm{M} 11602^{c}$ & E. schaudinni & Pará & EZ12 \\
\hline E14 & $\mathrm{MCHO} / \mathrm{BR} / 80 / \mathrm{M} 6159^{c}$ & E. schaudinni & Pará & EZ06 \\
\hline E15 & $\mathrm{MCHO} / \mathrm{BR} / 79 / \mathrm{M} 5725^{c}$ & E. schaudinni & Pará & EZ05 \\
\hline E09 & MBRA/PA/00/415P01 ${ }^{a}$ & Endotrypanum sp. & Panama & EZ01 \\
\hline \multicolumn{5}{|c|}{ Amazonian isolates } \\
\hline E01 & $\mathrm{MCHO} / \mathrm{BR} / 89 / \mathrm{RO} 9627^{d}$ & Endotrypanum $\mathrm{sp.}$ & Rondônia & EZ01 \\
\hline E02 & $\mathrm{MCHO} / \mathrm{BR} / 89 / \mathrm{RO} 1635^{d}$ & Endotrypanum sp. & Rondônia & EZ01 \\
\hline E03 & $\mathrm{MCHO} / \mathrm{BR} / 89 / \mathrm{RO} 1634^{d}$ & Endotrypanum sp. & Rondônia & EZ01 \\
\hline E04 & $\mathrm{MCHO} / \mathrm{BR} / 89 / \mathrm{RO} 1140^{d}$ & Endotrypanum sp. & Rondônia & EZ01 \\
\hline E05 & $\mathrm{MCHO} / \mathrm{BR} / 89 / \mathrm{RO} 1602^{d}$ & Endotrypanum $\mathrm{sp}$. & Rondônia & EZ01 \\
\hline E06 & $\mathrm{MCHO} / \mathrm{BR} / 89 / \mathrm{RO} 1471^{d}$ & Endotrypanum sp. & Rondônia & EZ01 \\
\hline E07 & $\mathrm{MCHO} / \mathrm{BR} / 89 / \mathrm{RO} 1583^{d}$ & Endotrypanum sp. & Rondônia & EZ01 \\
\hline E16 & $\mathrm{MCHO} / \mathrm{BR} / 85 / \mathrm{IM} 2260^{c}$ & Endotrypanum sp. & Pará & EZ07 \\
\hline $\mathrm{E} 17$ & $\mathrm{MCHO} / \mathrm{BR} / 85 / \mathrm{IM} 2382^{d}$ & Endotrypanum sp. & Rondônia & EZ09 \\
\hline E18 & $\mathrm{MCHO} / \mathrm{BR} / 85 / \mathrm{IM} 2384^{d}$ & Endotrypanum sp. & Rondônia & EZ01 \\
\hline E19 & $\mathrm{MCHO} / \mathrm{BR} / 85 / \mathrm{IM} 2389^{d}$ & Endotrypanum $\mathrm{sp}$. & Rondônia & EZ10 \\
\hline E21 & $\mathrm{MCHO} / \mathrm{BR} / 89 / \mathrm{IM} 3605^{d}$ & Endotrypanum sp. & Rondônia & EZ04 \\
\hline E22 & $\mathrm{MCHO} / \mathrm{BR} / 89 / \mathrm{IM} 3606^{d}$ & Endotrypanum sp. & Rondônia & EZ03 \\
\hline E31 & $\mathrm{MCHO} / \mathrm{BR} / 85 / \mathrm{IM} 2259^{c}$ & Endotrypanum sp. & Pará & EZ02 \\
\hline E32 & $\mathrm{MCHO} / \mathrm{BR} / 85 / \mathrm{IM} 2380^{d}$ & Endotrypanum sp. & Rondônia & EZ08 \\
\hline E33 & $\mathrm{MCHO} / \mathrm{BR} / 85 / \mathrm{IM} 2393^{d}$ & Endotrypanum sp. & Rondônia & EZ11 \\
\hline E36 & $\mathrm{MCHO} / \mathrm{BR} / 89 / \mathrm{IM} 3603^{d}$ & Endotrypanum sp. & Rondônia & EZ03 \\
\hline
\end{tabular}

Designations: Host $[\mathrm{M}=$ Mammalia: $\mathrm{BRA}=$ a: Bradypus infuscatus; $\mathrm{CHO}=$ Choloepus $\mathrm{sp} .($ b: C. hoffmanni; $c$ : $C$. didactylus; $d: C$. juruanus)] /country of origin/year of isolation/original code. Zymodeme (= strain variant); EZ = Endotrypanum zymodeme, classified by enzyme electrophoresis according to their mobility profiles (Franco et al. 1996). 
McMahon-Pratt 1996).

Typing of the Endotrypanum with MAbs was performed with an indirect immunofluorescence assay (IFAT), using whole fixed promastigotes as antigen (McMahon-Pratt et al. 1986) or by distinct immune binding assay systems such as indirect radioimmune assay (RIA) (Grimaldi et al. 1992), the ELISA technique (Jaffe \& McMahon-Pratt 1987), or dot-blot ELISA (Hawkes et al. 1982), using whole parasite lysates as antigen (Grimaldi et al. 1992). Characterization of the molecules associated with the specific antigenic determinants was performed by Western blot analysis (Jaffe \& McMahon-Pratt 1983). Briefly, the soluble antigen extracts were resolved by sodium dodecyl sulphate-polyacrylamide gel electrophoresis (SDSPAGE) using 10\% slab gels in non-reducing conditions, and electrophoretically transferred to nitrocellulose paper (Schleicher and Schuell, Keene, New Hampshire, USA). The techniques have been described in detail previously (Leon et al. 1992).

\section{RESULTS AND DISCUSSION}

In this paper, the characterization of representative strains of Endotrypanum, based on their reactivity patterns using specific MAbs to Endotrypanum (Lopes \& McMahon-Pratt 1989) or Leishmania (WHO 1993, Grimaldi \& McMahonPratt 1996) is presented. The genus Endotrypanum, analyzed in this study (Table I), may represent an heterogeneous complex of parasite species or strain variants, as classified by numerical zymotaxonomy (Franco et al. 1996).

Reactivity with monoclonal antibodies -Two MAbs (E-2, CXIV-3C7-F5 and E-24, CXXX-3G5F12) tested in these experiments were produced against membrane-enriched preparations of Endotrypanum species. In studies using a dot-blot radioimmune assay, these MAbs appear to be specific for the genus Endotrypanum, but monoclonal E-2 reacted exclusively with strain M6159 of $E$. schaudinni; no cross-reaction was observed when Leishmania species or other trypanosomatids were examined (Lopes \& McMahon-Pratt 1989). In this study, although the two clones reacted variably according to the test used (Fig. 1; Tables II-IV), in the ELISA (Table III) as well as IFAT (Table IV) both reacted with all Endotrypanum strains tested.

\section{TABLE II}

A comparison of the binding ${ }^{a}$ of Endotrypanumspecific monoclonal antibodies to reference strains and Endotrypanum isolates from the Amazon Region, Brazil

\begin{tabular}{|c|c|c|c|c|}
\hline \multirow{2}{*}{$\begin{array}{l}\text { Stock } \\
\text { code }\end{array}$} & \multirow[b]{2}{*}{ Species } & \multicolumn{3}{|c|}{ Monoclonal antibodies $b$} \\
\hline & & E-2 & E-24 & $\mathrm{CR}$ \\
\hline \multicolumn{5}{|c|}{ Reference strains } \\
\hline E11 & E. monterogeii & 10.7 & 18.3 & 6.5 \\
\hline E12 & E. schaudinni & 10.4 & 14.6 & 6.9 \\
\hline E15 & E. schaudinni & 9.1 & 8.3 & 6.6 \\
\hline E14 & E. schaudinni & 13.6 & 3.4 & 8.4 \\
\hline \multicolumn{5}{|c|}{ Amazonian isolates } \\
\hline E01 & Endotrypanum sp. & 6.4 & 5.3 & 6.1 \\
\hline E02 & Endotrypanum sp. & 3.6 & 6.3 & 15.0 \\
\hline E03 & Endotrypanum sp. & 7.1 & 5.5 & 6.1 \\
\hline E04 & Endotrypanum sp. & 7.6 & 11.6 & 8.7 \\
\hline E05 & Endotrypanum sp. & 7.1 & 3.4 & 9.7 \\
\hline E06 & Endotrypanum sp. & 4.0 & 2.3 & 4.6 \\
\hline E07 & Endotrypanum sp. & 8.3 & 8.6 & 8.7 \\
\hline E16 & Endotrypanum sp. & 8.4 & 9.3 & 6.6 \\
\hline E17 & Endotrypanum sp. & 14.5 & 6.5 & 5.7 \\
\hline E18 & Endotrypanum sp. & 8.0 & 10.0 & 6.0 \\
\hline E19 & Endotrypanum sp. & 4.8 & 2.6 & 5.8 \\
\hline E21 & Endotrypanum sp. & 10.9 & 26.4 & 9.6 \\
\hline E22 & Endotrypanum sp. & 9.0 & 5.2 & 10.0 \\
\hline E31 & Endotrypanum sp. & 8.6 & 6.1 & 17.1 \\
\hline E32 & Endotrypanum sp. & 3.5 & 2.8 & 7.6 \\
\hline E36 & Endotrypanum sp. & 7.2 & 7.0 & 9.8 \\
\hline
\end{tabular}

$a$ : results shown express the ratio of cpm bound monoclonal antibodies/cpm bound control; values $>3$ were considered positive.

$b$ : the hybridoma clones indicated above the lanes and their specificities are shown in Materials and Methods. $\mathrm{CR}$ (clone G2G4) is a cross-reactive monoclonal antibody used as a positive control throught these experiments.

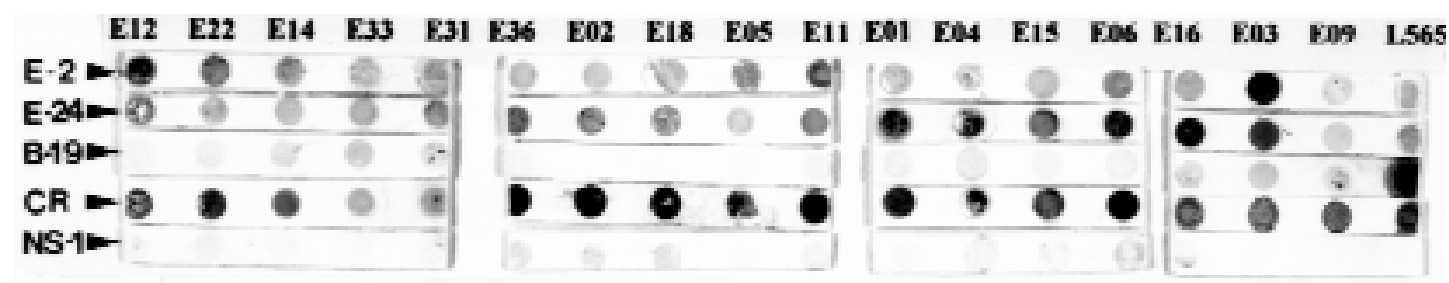

Fig. 1: specificity of monoclonal antibodies, E-2 (CXIV-3C7-F5) and E-24 (CXXX-3G5-F12) for the Endotrypanum strains, as shown by dot blot enzyme binding assay. The stock codes of the Endotrypanum strains analyzed are indicated above the lanes, and their origins are shown in Table I. Stock L565 is a Leishmania guyanensis reference strain (MHOM/BR/75/M4147) and clone B-19 (XLIV-5A2-B9) is considered specific for this parasite species. Clone CR (G2G4) is cross-reactive MAbs and was used as a positive control; NS-1, hybridoma culture supernatant (negative control). 
The analysis showed antigenic variation occurring among the Endotrypanum strains. Significant differences between the reactive patterns with specific MAbs could be observed among stocks (Tables II-III), but no qualitative or quantitative pattern could be consistently related to parasite origin (i.e., host species involved) or geographical area of isolation. These differences can be related with strain variation in the level of expression of certain antigenic determinants, as recognized by these MAbs. Variation in the sensitivity of the test may also occur due to the type of screening assay used.

IFAT studies were carried out to confirm the specificity and binding of the MAbs to the Endotrypanum surface determinants on intact parasites (Table IV). Each clone reacted in a continuous pattern on the surface of the promastigotes. Interestingly, clone E-24 produced the same immunofluorescent pattern of reaction (data not shown) with a parasite of sloth and rodent, $L$. equatorensis (Grimaldi et al. 1992). As noted with L. colombiensis (Kreutzer et al. 1991), two strains of L. equatorensis cross-reacted with MAbs T1 (clone XLVI-5B8-B3), T2 (XLVI, 4H12-C2), T3
(XLVI-5A5-D4), T4 (LXVIII-1A4-G1) and T8 (LXVII-3E12-F8) (Grimaldi et al. 1992), which were originally produced against parasites in the L. major/L. tropica complex (Jaffe \& McMahonPratt 1983). Moreover, using either IFAT (data not shown) or ELISA assay (Table III) the Endotrypanum strains reacted with MAbs specific to Leishmania, particularly with clones IS1-2C8C7 (T-12) and LXIX-2D8-D7 (T-11) which are $L$. major- or L. tropica-specific respectively (WHO 1993). Our data confirm a previously reported study (Shaw 1992) showing that a number of Endotrypanum strains cross-reacted with these MAbs (Jaffe \& McMahon-Pratt 1983) or monoclonal antibody (WIC 79.3) which recognizes lipophosphoglycan components of L. major (Handman et al. 1984). Based on this results, it appears that close antigenic links may exist between Endotrypanum and Leishmania. Work is now in progress to better define the phylogenetic relationship between these parasites. Whatever the explanation for the existence of these cross-reactive epitopes, these results indicate caution should be taken by all researchers working with field isolates.

\section{TABLE III}

Results of ELISA test ${ }^{a}$, employing monoclonal antibodies produced against Endotrypanum or Leishmania species, to reference strains and selected Endotrypanum isolates from the Amazon Region, Brazil

\begin{tabular}{|c|c|c|c|c|c|c|c|c|c|c|}
\hline \multirow{2}{*}{$\begin{array}{l}\text { Stock } \\
\text { code }\end{array}$} & \multirow[b]{2}{*}{ Species } & \multicolumn{9}{|c|}{ Monoclonal antibodies $b$} \\
\hline & & E-2 & E-24 & $\mathrm{CR}$ & $\mathrm{T}-12$ & $\mathrm{~T}-11$ & D-2 & M-7 & B-5 & B-20 \\
\hline \multicolumn{11}{|c|}{ Reference strains } \\
\hline E11 & E. monterogeii & $2 / 1$ & $1 / 1$ & $1 / 1$ & $2 / 2$ & & & & & \\
\hline E12 & E. schaudinni & $3 / 2$ & $2 / 2$ & $2 / 2$ & $1 / 1$ & $1 / 2$ & $1 / 1$ & $1 / 1$ & $1 / 1$ & $2 / 2$ \\
\hline E15 & E. schaudinni & $2 / 2$ & $2 / 2$ & & & & & & & \\
\hline E14 & E. schaudinni & $2 / 2$ & $2 / 2$ & $2 / 2$ & $1 / 1$ & $1 / 1$ & $1 / 1$ & $1 / 1$ & $1 / 1$ & $1 / 1$ \\
\hline E09 & Endotrypanum sp. & $1 / 2$ & & $1 /$ & $1 / 2$ & & & & & \\
\hline \multicolumn{11}{|c|}{ Amazonian isolates } \\
\hline E01 & Endotrypanum sp. & $2 / 2$ & $2 / 1$ & $2 / 2$ & & $4 / 4$ & & & & \\
\hline E02 & Endotrypanum sp. & $1 / 1$ & $1 / 1$ & $1 / 1$ & & & & & & \\
\hline E03 & Endotrypanum sp. & $2 / 2$ & $1 / 2$ & $1 / 1$ & & & & & & \\
\hline E04 & Endotrypanum sp. & $2 / 2$ & $1 / 1$ & $1 / 1$ & $1 / 2$ & & & & & \\
\hline E06 & Endotrypanum sp. & $2 / 2$ & $1 / 1$ & $2 / 2$ & $1 / 2$ & & & & & \\
\hline E07 & Endotrypanum sp. & $1 / 1$ & $2 / 3$ & $3 / 5$ & & $7 / 7$ & & & & \\
\hline E16 & Endotrypanum sp. & $1 / 1$ & $1 / 1$ & $1 /$ & $1 / 1$ & & & & & \\
\hline E18 & Endotrypanum sp. & $2 / 2$ & $1 / 1$ & $1 / 1$ & & & & & & \\
\hline E19 & Endotrypanum sp. & $1 / 1$ & $1 / 1$ & $1 / 1$ & & & & & & \\
\hline E21 & Endotrypanum sp. & $1 / 1$ & $1 / 1$ & $1 /$ & $3 / 3$ & $1 / 3$ & & & & \\
\hline E22 & Endotrypanum sp. & $1 / 2$ & $2 / 1$ & $1 / 1$ & & & & & & \\
\hline E31 & Endotrypanum sp. & $6 / 7$ & $3 / 2$ & $2 / 2$ & $5 / 7$ & $1 / 2$ & $2 / 2$ & $1 / 2$ & & \\
\hline E32 & Endotrypanum sp. & $3 / 3$ & $2 / 2$ & $1 / 1$ & $2 / 4$ & & & & & \\
\hline E36 & Endotrypanum sp. & $3 / 3$ & $1 / 1$ & $1 /$ & $2 / 2$ & & & & & \\
\hline
\end{tabular}

$a$ : the tabulated numbers (duplicate tests) correspond to the OD ranges at absorbance $405 \mathrm{~nm}$. Values ${ }^{3} 1$ were considered positive (all blanks equal negative results).

The range were: $0=0$ to $0.130 ; 1=0.131$ to $0.317 ; 2=0.318$ to $0.504 ; 3=0.505$ to $0.691 ; 4=0.692$ to $0.878 ; 5=0.879$ to $1.065 ; 6=1.066$ to $1.252 ; 7=1.253$ to 1.439 .

$b$ : the hybridoma clones indicated above the lanes and their specificities are shown in Materials and Methods. 
TABLE IV

Specificity of monoclonal antibodies, E-2 (CXIV33C7-F5) and E-24 (CXXX-3G5-F12) for the Endotrypanum strains by indirect immunofluorescence $^{a}$

\begin{tabular}{|c|c|c|}
\hline Stock & Species & Monoclonal antibodies \\
\hline code & & $\begin{array}{ll}\text { E2 } & \text { E24 }\end{array}$ \\
\hline
\end{tabular}

Endotrypanum reference strains

$\begin{array}{llll}\text { E11 } & \text { E. monterogeii } & ++ & +++ \\ \text { E12 } & \text { E. schaudinni } & ++ & +++ \\ \text { E15 } & \text { E. schaudinni } & ++ & +++ \\ \text { E14 } & \text { E. schaudinni } & ++++ & ++ \\ \text { E09 } & \text { Endotrypanum sp. } & ++ & ++\end{array}$

Endotrypanum isolates

E01 Endotrypanum sp. $\quad+++$

E02 Endotrypanum sp. $+++\quad++$

E03 Endotrypanum sp. $\quad++\quad+++$

E04 Endotrypanum sp. $\quad++\quad+++$

E05 Endotrypanum sp. $\quad++\quad++$

E06 Endotrypanum sp. $\quad++\quad+++$

E07 Endotrypanum sp. $\quad+\quad++$

E16 Endotrypanum sp. $\quad++\quad++$

E17 Endotrypanum sp. +++ +++

E18 Endotrypanum sp. ++ +++

E19 Endotrypanum sp. $\quad++\quad+++$

E21 Endotrypanum sp. $\quad+\quad++$

E22 Endotrypanum sp. $\quad+\quad++$

E31 Endotrypanum sp. $\quad++\quad+++$

E32 Endotrypanum sp. $\quad+\quad+$

E33 Endotrypanum sp. ++ +++

E36 Endotrypanum sp. ++ ++

a: scored: $(-)=$ negative; $(+)=$ positive; $(++)=$ strong reaction; $(+++)$ and $(++++)=$ very strong reaction.
Identification of Endotrypanum antigens by $M A b s$ - Fig. 2 shows the results of the Western blot analysis identifying the molecules associated with the antigenic determinants recognized by MAbs E2 and E-24. While E-2 recognized two weak components with an apparent molecular mass of $24 \mathrm{kD}$ and $30 \mathrm{kD}$, the latter MAb identified multiple molecular components with apparent relative mobility (Mr) values ranging from 25 to more than $80-\mathrm{kDa}$. These results are consistent with previous studies using these MAbs (Lopes \& McMahon-Pratt 1989). However, variation occurred between strains analyzed in this study, in either the Mr, intensity or number of components observed. These observations indicated that differences existed either in the epitope density or molecular forms associated with the specific antigenic determinants and therefore allowed the assignment of the strains to specific antigenic groups. These strains formed a polymorphic population according to their enzyme profiles and were grouped into 12 zymodemes. However, all of the isolates from the same species of sloth (C. juruanus) and geographical origin (Rondônia, Brazil) had the same enzymic profile (Franco et al. 1996). In contrast, this group of parasites (zymodeme EZ01) when characterized by serodeme analysis, appeared to be a heterogenous population. An explanation for these differences could be related to any of the following reasons: (1) the possibility of cross-contamination or mixed-up of samples in our laboratory, (2) a mixed infection, and (3) the fact that the two techniques measure different properties of parasites. Ultimately, cloning procedures, as well as genetic differences (DNA) may need to be established for these parasites.

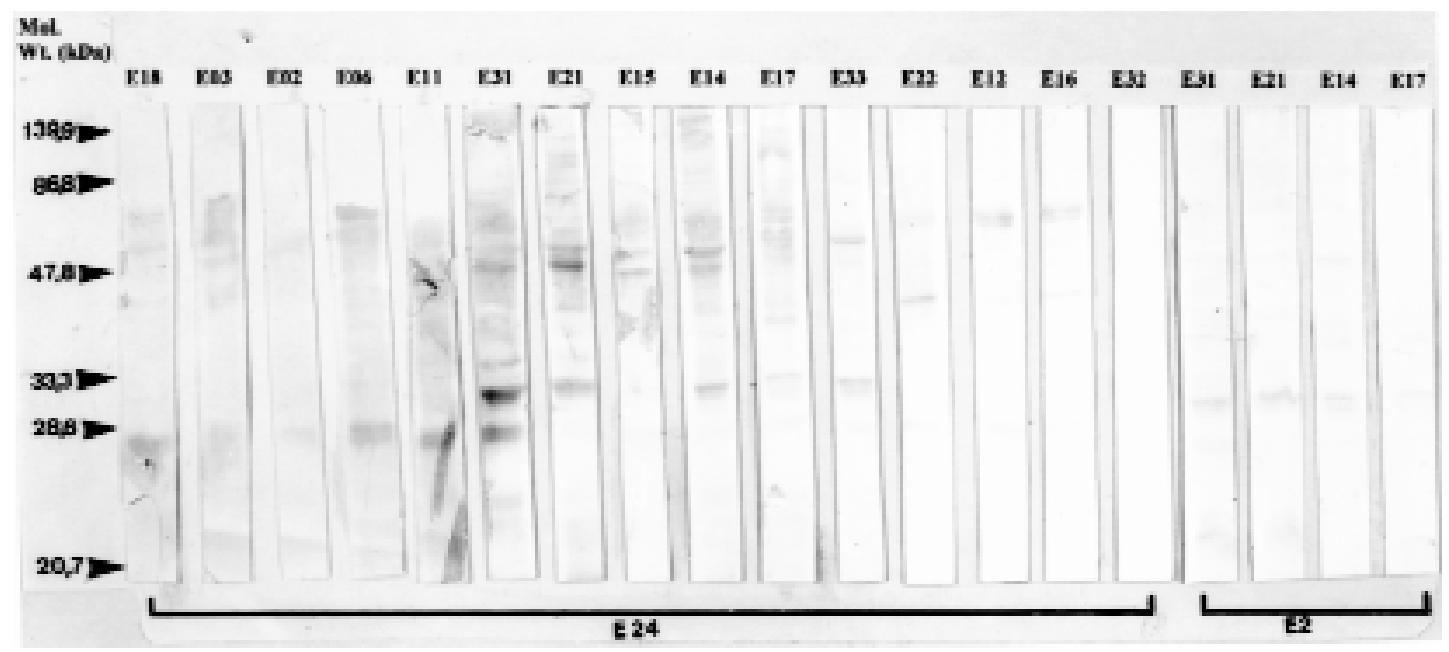

Fig. 2: western blot analyses of promastigotes homogenates from representative strains of Endotrypanum using monoclonal antibodies E-2 (CXIV-3C7-F5) and E-24 (CXXX-3G5-F12). The stock codes of the strains analyzed are indicated above the lanes, and their origins are shown in Table I. Molecular weights are indicated in $\mathrm{kDa}$ beside the figure. 
In conclusion, we have classified a total of 17 Amazon Endotrypanum isolates (from the states of Rondônia and Pará) through the application of techniques employing specific MAbs in comparison with standard reference strains. Characterization of Endotrypanum with specific MAbs is an additional approach useful to group/differentiate further among these parasites, but problems related to the identification of stocks (the described species are indistinguishable) were encountered using the MAbs employed in this study. Our results confirm previous studies (Lopes et al. 1990, Franco et al. 1996) reporting heterogeneity in this genus.

\section{ACKNOWLEDGMENTS}

To Dr JJ Shaw (Evandro Chagas Institute, PA, BR) for the donation of reference strains.

\section{REFERENCES}

Bradford MM 1976. A rapid and sensitive method for the quantitation of microgram quantities of protein utilizing the principle of protein-dye binding. Anal Biochem 72: 248-254.

Croft SL, Chance ML, Gardener PJ 1980. Ultrasctructural and biochemical characterization of stocks of Endotrypanum. Ann Trop Med Parasitol 74: 585-589.

Fernandes O, Degrave W, Campbell DA 1993. The miniexon gene: a molecular marker for Endotrypanum schaudinni. Parasitology 107: 219-224.

Franco AMR, Momen H, Naiff, RD, Moreira CFS, Deane MP, Grimaldi Jr G 1996. Enzyme polymorphism in Endotrypanum and numerical analysis of isoenzyme data. Parasitology 113: 39-48.

Greig SR, Akinsehinwa FA, Ashall F, Lainson R, Shaw JJ, Miles MA, Barker DC 1989. The feasibility of discrimination between Leishmania and Endotrypanum using total DNA probes. Trans $R$ Soc Trop Med Hyg 83: 196-197.

Grimaldi Jr G, McMahon-Pratt D 1996. Monoclonal antibodies for the identification of New World Leishmania species. Mem Inst Oswaldo Cruz 91: 37-42.

Grimaldi Jr G, Tesh RB 1993. Leishmaniases of the New World: Current concepts and implications for future research. Clin Microbiol Rev 6: 230-250.

Grimaldi Jr G, Kreutzer RD, Hashiguchi Y, Gomez EA, Mimory T, Tesh RB 1992. Description of Leishmania equatoriensis $\mathrm{sp}$. n. (Kinetoplastida: Trypanosomatidae), a new parasite infecting arboreal mammals in Ecuador. Mem Inst Oswaldo Cruz 87: 221-228.

Handman E, Greenblatt CL, Goding JW 1984. An ampiphatic sulphated glycoconjugate of Leishmania: Characterization with monoclonal antibodies. EMBO J 3: 2301-2306.

Hawkes R, Niday E, Gordon J 1982. A dotimmunobinding assay for monoclonal and other antibodies. Anal Biochem 119: 142-147.

Herrer A, Christensen HA 1980. Leishmania braziliensis in the Panamanian two-toed sloth, Choloepus hoffmanni. Am J Trop Med Hyg 29: 1196-1200.

Jaffe CL, McMahon-Pratt D 1983. Monoclonal antibodies specific for Leishmania tropica. I. Characterization of antigens associated with stage- and speciesspecific determinants. J Immunol 131: 1987-1993.
Jaffe CL, McMahon-Pratt D 1987. Serodiagnostic assay for visceral leishmaniasis employing monoclonal antibodies. Trans R Soc Trop Med Hyg 81: 587-594.

Kreutzer RD, Corredor A, Grimaldi Jr G, Grogl M, Rowton ED, Young DG, Morales A, McMahon-Pratt D, Guzman H, Tesh RB 1991. Characterization of Leishmania colombiensis sp. n. (Kinetoplastida: Trypanosomatidae), a new parasite infecting humans, animals, and phlebotomine sand flies in Colombia and Panama. Am J Trop Med Hyg 44: 662-675.

Leon LL, Machado GMC, Barral A, Carvalho-Paes LE de, Grimaldi Jr G 1992. Antigenic differences among Leishmania amazonensis isolates and their relationship with distinct clinical forms of the disease. Mem Inst Oswaldo Cruz 87: 229-234.

Lopes AHCS, McMahon-Pratt D 1989. Monoclonal antibodies specific for members of the genus Endotrypanum. J Protozool 36: 354-361.

Lopes AHCS, Iovannisci D, Petrillo-Peixoto M, McMahon-Pratt D, Beverley SM, 1990. Evolution of nuclear DNA and the occurrence of sequences related to new small chromosomal DNAs in the trypanosomatid genus Endotrypanum. Mol Biochem Parasitol 40: 151-162.

McMahon-Pratt D, Jaffe CL, Bennett E, David JR, Grimaldi Jr G 1986. Studies employing monoclonal antibodies for the analysis of the genus Leishmania Ross, 1903, p. 173-178. In Coll Intern CNRS/ INSERM, 1984. Leishmania. Taxonomie et Phylogenese. Applications ecoepidemiologiques. IMEEE, Montpellier, France.

Medina-Acosta E, Franco AMR, Jansen AM, Sampol M, Nevez N, Pontes de Carvalho L, Grimaldi Jr G, Nussenzweig V 1994. Trans-sialidase and sialidase activities discriminate between morphologically indistinguishable trypanosomatids. Eur J Biochem 225: 333-339.

Miles MA, Arias JR, Valente SA, Naiff RD, de Souza AA, Povoa MM, Lima JA, Cedillos RA 1983. Vertebrate hosts and vectors of Trypanosoma rangeli in the Amazon Basin of Brazil. Am J Trop Med Hyg 32: 1251-1259.

Montero-Gei F 1956. Contribucion al estudio de Endotrypanum schaudinni (Trypanosomatidae). Rev Biol Trop 4: 41-68.

Shaw JJ 1969. The haemoflagellates of sloths. London School of Hygiene and Tropical Medicine Memoir 13, HK Lewis Co Ltd, London, 132 pp.

Shaw JJ 1985. The hemoflagellates of sloths, vermilingues (anteaters), and armadillos, p. 279-292. In GG Montegomery, The evolution and ecology of armadillos, sloths and vermilingues. Smithsonian Institution, Washington, D.C.

Shaw JJ 1992. Endotrypanum, a unique intraerythrocytic flagellate of New World tree sloths. An evolutionary link or an evolutionary backwater? Ciência e Cultura 44: 107-116.

WHO 1993. Report from a workshop on Use of monoclonal antibodies in the identification of Leishmania of medical importance in latin America. Cali, Colombia, Dec 5-10.

Zeledón R, Ponce C, Ponce E de 1975. The isolation of Leishmania braziliensis from sloths in Costa Rica. Am J Trop Med Hyg 24: 706-707. 